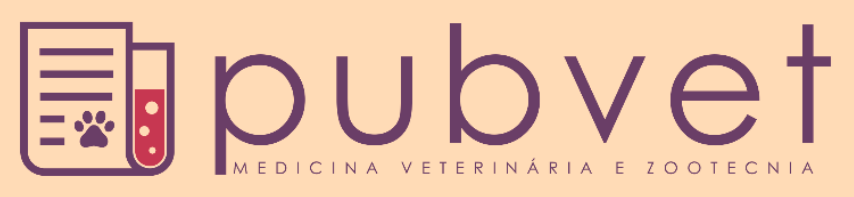

https://doi.org/10.31533/pubvet.v13n4a313.1-5

\title{
Contagem bacteriana total do leite cru refrigerado em função do período do ano
}

\author{
Rafael Lennini Lemes de Queiroz $^{1} \bullet$, Karyne Oliveira Coelho ${ }^{2 *} \bullet$, Allan Afonso \\ $\operatorname{Passos}^{2} \bullet$, Luciana dos Reis Valadão ${ }^{\circ} \bullet$, Renata Vaz Ribeiro ${ }^{\bullet} \bullet$ \\ ${ }^{I}$ Pós- Graduando do Curso de Especialização em Produção Animal Universidade Estadual de Goiás, Campus São Luís de \\ Montes Belos. São Luís de Montes Belos, Goiás, Brasil. ${ }^{2}$ Professora da Universidade Estadual de Goiás, Campus São Luís de \\ Montes Belos, São Luís de Montes Belos, Goiás, Brasil. ${ }^{3}$ SENAR/Goiás. ${ }^{4}$ Programa de Pós-Graduação "Mestrado" em \\ Zootecnia - Universidade Federal de Goiás, Goiânia, Goiás, Brasil. \\ *Autor para correspondência: karyne.coelho@ueg.br
}

\begin{abstract}
Resumo. Objetivou-se avaliar o efeito do período do ano sobre a contagem bacteriana total do leite cru refrigerado. Para isso, foram coletadas amostras de leite cru diretamente do tanque de expansão de 30 propriedades no período de abril a dezembro. As amostras foram analisadas quanto à contagem bacteriana total. Os resultados foram avaliados através do Teste de Student a 5\%. Houve diferença significativa entre o período chuvoso e o seco para as variáveis contagem bacteriana total e \% de não conformidade, sendo que no período chuvoso esses índices apresentaram-se superiores. Os resultados apontam como principais problemas da qualidade do leite cru refrigerado os relacionados à higiene na obtenção e manutenção do produto, fazendo necessária uma intervenção adequada, para que se tenha controle da contagem bacteriana total independente da época do ano.
\end{abstract}

Palavras-chave: Bovinocultura leiteira, CBT, chuvas, higiene

\section{Total bacterial count of raw milk refrigerated as a function of the period of the year}

\begin{abstract}
The objective of this study was to evaluate the effect of the season on the total bacterial count of refrigerated raw milk. For this, samples of raw milk collected directly from the 30-unit expansion tank from April to December. The results evaluated through Student's test at 5\%. Sample analyzed for total bacterial count. There was a significant difference between the rainy and dry periods for total bacterial count variables and \% of nonconformities, and in the rainy season these rates were higher. The results indicate that the main problems of the quality of refrigerated raw milk are those related to hygiene in the obtaining and maintenance of the product, requiring an adequate intervention, so that for total bacterial count control is independent of the time of the year.
\end{abstract}

Keywords: TBC, dairy cattle, hygiene, rains

\section{Recuento bacteriano total de la leche cruda refrigerada en función del período del año}

Resumen. Se objetivó evaluar el efecto de la estación del año sobre el conteo bacteriano total de la leche cruda refrigerada. Para ello se recolectaron muestras de leche cruda directamente del tanque de expansión de 30 propiedades en el período de abril a diciembre. Las muestras se analizaron en cuanto al recuento bacteriano total. Los resultados fueron evaluados a través del Test de Student al 5\%. Hubo diferencia significativa entre el período 
lluvioso y el seco para las variables recuento bacteriano total y \% de no conformidad, siendo que en el período lluvioso estos índices se presentaron superiores. Los resultados apuntan como principales problemas de la calidad de la leche cruda refrigerada los relacionados a la higiene en la obtención y mantenimiento del producto, haciendo necesaria una intervención adecuada, para que se tenga control del recuento bacteriano total independiente de la época del año.

Palabras clave: $\mathrm{CBT}$, ganadería lechera, lluvias, higiene

\section{Introdução}

O número de bactérias contidas no leite é expresso em unidades formadoras de colônias por mililitro de leite (UFC/mL). Leite com alta CBT (contagem bacteriana total) pode provocar um impacto negativo em toda a cadeia produtiva, sendo responsável por problemas como: alterações no sabor e odor do leite, desvalorização pelas empresas que realizam o pagamento por qualidade, alterações no tempo de validade do leite in natura e dos produtos lácteos e, até mesmo problemas, de saúde pública. De forma geral, as principais fontes de contaminação direta de bactéria para o leite cru são os quartos mamários, úbere e pele dos tetos infectados com mastite, utensílios e/ou equipamentos sujos que entrem em contato com o leite (Souza et al., 2010). A CBT indica a qualidade microbiológica do leite e a adoção de condições gerais de higiene e refrigeração do leite, desde sua obtenção até o envio para a indústria. Várias etapas podem ser consideradas críticas na produção do leite acarretando o aumento da CBT, como por exemplo, o tipo de ordenha e sua falta de higiene (Taffarel et al., 2015), período do ano (seca ou águas) (Bueno et al., 2005; Henrichs et al., 2014), a qualidade da água utilizada na limpeza (Cissé et al., 2018), a temperatura e o tempo de armazenagem do leite (Taffarel et al., 2015), dentre outros.

Diversos autores estudaram a influência da sazonalidade na qualidade microbiológica do leite (Côrtes et al., 2010; Delgado-Pertíñez et al., 2013; Jurie et al., 2007; Larsen et al., 2010; Rodrigues et al., 2012; Roma Júnior et al., 2009). No entanto, no estado de Goiás, que possui duas épocas bem definidas em relação à presença de chuva, poucos trabalhos foram realizados a fim de definir a qualidade do leite produzido. $\mathrm{O}$ efeito da sazonalidade é resultado principal da variação pluviosidade versus temperatura entre o período de inverno e o período de verão (Souza et al., 2010).

Os critérios normativos são bastante rígidos, mas caso a qualidade do leite não seja legalmente satisfatória, pode prejudicar não só o rendimento industrial, como também a segurança alimentar e a remuneração do produtor, deste modo, objetivou-se avaliar o efeito do período do ano, seco ou chuvoso, sobre a CBT do leite cru refrigerado.

\section{Material e métodos}

Obtiveram-se amostras de leite cru em 30 unidades agrícolas familiares produtoras de leite, localizadas nos municípios de São Luís de Montes Belos, Adelândia São Luís de Montes Belos, Firminópolis, Turvânia, Anicuns, São João da Paraúna, Aurilândia, Córrego do Ouro e Sanclerlândia. As propriedades foram escolhidas aleatoriamente, não priorizando nenhum tipo ou características de produção. Foram seis coletas durante o ano, sendo três no período seco (abril, junho e julho) e três no período chuvoso (outubro, novembro e dezembro). Com médias de índice pluviométrico de 12,66 mm e $194 \mathrm{~mm}$, temperatura de $21,8^{\circ} \mathrm{C}$ e $27,6{ }^{\circ} \mathrm{C}$, para os períodos, secos e chuvoso, respectivamente.

No total, foram coletadas 180 amostras, ou seja, 90 amostras por época de coleta, sendo que de cada propriedade retiraram-se, com coletores de aço inoxidável, um pool de $40 \mathrm{~mL}$ do leite acondicionado nos tanques de refrigeração, que foram armazenados em frascos esterilizados contendo o conservante azidiol, visando o envio para realização das análises de contagem bacteriana total (CBT), que foram realizadas no laboratório de qualidade do leite da Escola de Veterinária e Zootecnia da Universidade Federal de Goiás (LQL/EVZ/UFG). A determinação da CBT foi realizada pelo princípio analítico de citometria de fluxo.

Os resultados de CBT foram logarizados e realizou-se o Teste de Student para avaliar o efeito do período do ano sobre a CBT, adotou-se $\mathrm{P}>0,05$. Também foi realizada a média geométrica dos resultados (CBT) avaliada nos períodos analisados, visando determinar a frequência relativa de amostras em desacordo com o padrão, ou seja, $300 \mathrm{mil} \mathrm{UFC/mL}$. 


\section{Resultados e discussão}

Os resultados encontrados nesse estudo em relação ao $\log$ da CBT e percentuais de não conformidade podem ser observados na Tabela 1.

Tabela 1. Log da contagem bacteriana total e percentual de não conformidade de acordo com o período do ano, chuvoso ou seco, para amostras de leite cru refrigerado

\begin{tabular}{lcc}
\hline Período & CBT $(\mathrm{UFC} / \mathrm{mL}) \log$ & \% de Não Conformidade* \\
\hline Seco & $4,22^{\mathrm{a}}$ & $20 \%$ \\
Chuvoso & $5,39^{\mathrm{b}}$ & $30 \%$ \\
\hline
\end{tabular}

Letras diferentes na mesma coluna diferem entre si para $p<0,05 . *$ Para a avaliação da não conformidade realizou-se a média geométrica dos três resultados obtidos em cada período do ano (IN 62).

Houve diferença entre o período chuvoso e o seco para a variável CBT, com maior contagem e percentual de não conformidade no período chuvoso. Esse resultado pode ser explicado, devido provavelmente que na época de chuvas, a lama pode se acumular nos currais e salas de ordenha, as tetas dos animais ficam mais propensas a apresentarem sujidades, podendo assim contribuir para uma contaminação inicial do leite (Jainudeen \& Hafez, 2004; Pereira et al., 2010). Martins \& Pieruzzi (2011) relataram que o período chuvoso favorece à contaminação ambiental, o acúmulo de lama nas instalações e à maior ocorrência de tetos sujos no momento da ordenha. Além disso, a temperatura ambiente favorece o crescimento bacteriano e, portanto, pode acarretar a contaminação e um maior crescimento de bactérias no leite (Martins \& Pieruzzi, 2011). No entanto, se as práticas de manejo de ordenha forem adequadas, espera-se que se tenha uma uniformidade da CBT em todos os períodos do ano.

Os resultados encontrados neste trabalho corroboram com aos observados por Cassol et al. (2010) os quais determinaram a qualidade do leite de 30 unidades agrícolas familiares produtoras de leite, localizadas nos municípios de Juramento e Montes Claros, Norte do Estado de Minas Gerais, sendo realizadas quatro coletas durante um ano, duas na época de chuva (dezembro/2010 e outubro/2011) e duas na época da seca (março/2011 e junho/2011), e obtiveram como resposta que na época das chuvas há um aumento de microrganismos como psicrotróficos, Coliformes e Enterococcus.

Guimarães (2017) ao estudar a sazonalidade na qualidade do leite cru refrigerado na Microrregião de Catalão/Goiás nas épocas de seca (maio a setembro) e chuvas (outubro a abril), observou que os valores de CBT foram menores na época da seca. Simioni et al. (2014) analisaram as variações sazonais da qualidade do leite no Oeste de Santa Catarina de acordo com as estações do ano, utilizando dados de 799 produtores de leite, nos períodos de verão (dezembro a fevereiro), outono (março a maio), inverno (junho a agosto) e primavera (setembro a novembro), e observaram valores de CBT maiores no inverno, seguidas pela primavera e verão, sendo o período de outono o CBT mais baixo. Nota-se que a CBT é maior nos meses mais frios, época em que a umidade é intensa no Oeste de Santa Catarina. Fagnani et al. (2014) coletaram durante 24 meses, 1263 amostras de leite cru sendo: 220 amostras no outono, 228 amostras no inverno, 661 amostras na primavera e 154 amostras no verão. Como resultado os autores observaram que na primavera a CBT foi maior $(\mathrm{p}<0,05)$ que as demais estações do ano, sendo de 3,15 $(\log \mathrm{CBT})$ contra o menor de 2,83 $(\log \mathrm{CBT})$ para o outono. Roma Júnior et al. (2009) encontraram maiores valores de CBT na primavera e menores resultados no outono e inverno $\left(207 \times 10^{4}, 57 \times 10^{4}\right.$, $60 \times 10^{4} \mathrm{UFC} / \mathrm{mL}$ respectivamente) em seus estudos em propriedades nos estados de Minas Gerais, Rio de janeiro e São Paulo, em que analisaram 2.970 amostras de leite.

Bueno et al. (2008), Lacerda et al. (2010) e Paiva et al. (2012) também encontraram maiores contagens de CBT nos meses chuvosos em seus estudos. Diferentemente dos resultados apresentados por outros autores. No trabalho de Campos et al. (2016), ao avaliarem o efeito das estações do ano sobre a qualidade higiênico-sanitária do leite obtido em diferentes sistemas de produção no estado do Rio Grande do Norte, foi observado uma diferença considerável entre os meses de abril a junho $(398,08$ $\mathrm{UFC} / \mathrm{mL}$ ) contra os meses de outubro a dezembro (100,78 UFC/mL). Esse resultado é explicado pelos autores através da escassez pluviométrica que caracterizou os anos de 2011 e 2012, fazendo com que os produtores priorizassem o direcionamento dos recursos financeiros para a aquisição de alimentos para os rebanhos, dificultando, por motivos de custos, a execução de boas práticas de higiene e ordenha o que ocasionaria o aumento da CBT. Resultados diferentes foram encontrados por Dias et al. (2015) que 
realizaram estudos com 20 propriedades leiteiras da região Sudoeste do Estado de Goiás, a fim de estudar a sazonalidade dos componentes do leite e concluíram que não houve diferença entre os valores de CBT em relação a época do ano. Andrade et al. (2014) também não observaram diferença entre o período seco e o período chuvoso para o índice CBT no seu estudo no estado do Rio Grande do Norte.

Em relação à porcentagem de propriedades não conformes, também houve um número maior na estação chuvosa do ano corroborando as observações detectadas por Fagnani et al. (2014) e Guimarães (2017). Como consequência, o leite com elevada CBT pode causar acidez, queda no rendimento e deterioração dos derivados. Estes resultados expressam a relevância de programas que penalizam pelas metas não alcançadas, mas que também bonificam pela qualidade do leite como incentivo aos produtores para a produção do leite de boa qualidade. No entanto, deve-se ponderar que o percentual de amostras NC está em abaixo do que relatado por diferentes pesquisadores no Brasil (Andrade et al., 2014; Bueno et al., 2005; Fagnani et al., 2014); isto provavelmente representa um indício da influência positiva das Instruções Normativas sobre a cadeia produtiva de lácteos, ou mesmo a conscientização dos produtores e demais agentes integrantes do setor, quanto à necessidade e vantagens da melhoria da qualidade do leite cru refrigerado produzido no Brasil e disponibilizado ao mercado industrial e consumidor (Guimarães, 2017).

\section{Conclusão}

A CBT e porcentagem de propriedades não conformes foram maiores no período chuvoso, o que demonstra à necessidade de intervenção quanta a adoção de boas práticas de obtenção e armazenamento do leite; intensificando os cuidados relativos à contaminação ambiental e à assepsia dos tetos dos animais ordenhados.

\section{Referências bibliográficas}

Andrade, K. D., Rangel, A. H. N., Araújo, V. M., Medeiros, H. R., Bezerra, K. C., Bezerril, R. F. \& Lima Júnior, D. M. (2014). Qualidade do leite bovino nas diferentes estações do ano no estado do Rio Grande do Norte. Revista Brasileira de Ciência Veterinária, 21(3):213-216.

Bueno, V. F. F., Mesquita, A. J., Nicolau, E. S., Oliveira, A. N., Oliveira, J. P., Neves, R. B. S., . . . Thomaz, L. W. (2005). Contagem celular somática: relação com a composição centesimal do leite e período do ano no Estado de Goiás. Ciência Rural, 35(4):848-854.

Bueno, V. F. F., Mesquita, A. J., Oliveira, A. N., Nicolau, E. S. \& Neves, R. B. S. (2008). Contagem bacteriana total do leite: relação com a composição centesimal e período do ano no Estado de Goiás. Revista Brasileira de Ciências Veterinárias, 15(1):40-44.

Campos, P. P. L. E., Rangel, A. H. N., Borba, L. H. F., Urbano, S. A., Novaes, L. P., Galvão Júnior, J. G. B., . . Aguiar, E. M. (2016). Quality indicators of tank milk in different production systems of tropical regions. Semina: Ciências Agrárias, 37(4):2819-2830.

Cassol, D. M. S., Sandoval, G. A. F., Pericole, J. J., Gil, P. C. N. \& Marson, F. A. (2010). Introdução agentes da mastite diagnóstico e tratamento. A Hora Veterinária, 29(175):1-5.

Cissé, H., Sawadogo, A., Kagambèga, B., Zongo, C., Traoré, Y. \& Savadogo, A. (2018). Milk production and sanitary risk along the food chain in five cities in Burkina Faso. Urban Science, 2(57):1-16.

Côrtes, C., Kazama, D. C. S., Kazama, R., Gagnon, N., Benchaar, C., Santos, G. T., . . Petit, H. V. (2010). Milk composition, milk fatty acid profile, digestion, and ruminal fermentation in dairy cows fed whole flaxseed and calcium salts of flaxseed oil 1. Journal of Dairy Science, 93(7):3146-3157. doi: 10.3168/jds.2009-2905

Delgado-Pertíñez, M., Gutiérrez-Peña, R., Mena, Y., Fernández-Cabanás, V. M. \& Laberye, D. (2013). Milk production, fatty acid composition and vitamin E content of Payoya goats according to grazing level in summer on Mediterranean shrublands. Small Ruminant Research, 114(1):167-175.

Dias, M., Assis, A. C. F., Nascimento, V. A., Saenz, E. A. C. \& Lima, L. A. (2015). Sazonalidade dos componentes do leite e o programa de pagamento por qualidade. Enciclopédia Biosfera, 11(21):1712-1727. 
Fagnani, R., Battaglini, A. P. P., Beloti, V., Schuck, J., Seixas, F. N. \& Carraro, P. E. (2014). Parâmetros físico-químicos e microbiológicos do leite em função da sazonalidade. Revista do Instituto de Laticínios Cândido Tostes, 69(3):173-180.

Guimarães, A. J. S. (2017). Avaliação da qualidade do leite cru refrigerado em relação ao enquadramento legal e o efeito da sazonalidade sobre o preço pago aos produtores. Master of Science, Universidade Federal de Goiás, Goiânia, Goiás.

Henrichs, S. C., Macedo, R. E. F. \& Karam, L. B. (2014). Influência de indicadores de qualidade sobre a composição química do leite e influência das estações do ano sobre esses parâmetros. Revista Acadêmica: Ciência Animal, 12(3):199-208.

Jainudeen, M. R. \& Hafez, E. S. E. (2004). Bovinos e Bubalinos. In E. S. E. Hafez \& B. Hafez (Eds.), Reprodução Animal (pp. 159-167). Barueri, São Paulo, Brasil: Manole, 2004.

Jurie, C., Cassar-Malek, I., Bonnet, M., Leroux, C., Bauchart, D., Boulesteix, P., . . Hocquette, J. F. (2007). Adipocyte fatty acid-binding protein and mitochondrial enzyme activities in muscles as relevant indicators of marbling in cattle. Journal of Animal Science, 85(10):2660-2669.

Lacerda, L. M., Mota, R. A. \& Sena, M. J. (2010). Contagem de células somáticas, composição e contagem bacteriana total do leite de propriedades leiteiras nos municípios de Miranda do Norte, Itapecurú-Mirim e Santa Rita, Maranhão. Arquirvo do Instituto de Biologia, 77(2):209-215.

Larsen, M. K., Nielsen, J. H., Butler, G., Leifert, C., Slots, T., Kristiansen, G. H. \& Gustafsson, A. H. (2010). Milk quality as affected by feeding regimens in a country with climatic variation. Journal of Dairy Science, 93(7):2863-2873. doi: https://doi.org/10.3168/jds.2009-2953.

Martins, M. F. \& Pieruzzi, P. A. P. (2011). Bem estar animal na bovinocultura leiteira. In M. V. D. Santos, L. F. P. Silva, F. P. Rennó \& R. D. Albuquerque (Eds.), Novos desafios da pesquisa em nutrição e produção animal. Itirapina, São Paulo, Brasil: VTN.

Paiva, C. A. V., Cerqueira, M. M. O. P., Souza, M. R. S. \& Lana, A. M. Q. (2012). Annual evolution of raw milk quality processed in a dairy industry of Minas Gerais state, Brazil. Arquivo Brasileiro de Medicina Veterinária e Zootecnia, 64(2):471-479.

Pereira, E. S., Pimentel, P. G., Queiroz, A. C. \& Mizubuti, I. Y. (2010). Novilhas leiteiras (Vol. 1). Fortaleza, Ceará: Graphiti Gráfica e Editora Ltda.

Rodrigues, N. P. A., Givisiez, P. E. N., Queiroga, R. C. R. E., Azevedo, P. S., Gebreyes, W. A. \& Oliveira, C. J. B. (2012). Milk adulteration: Detection of bovine milk in bulk goat milk produced by smallholders in northeastern Brazil by a duplex PCR assay. Journal of Dairy Science, 95(5):27492752.

Roma Júnior, L. C., Montoya, J. F. G., Martins, T. T., Cassoli, L. D. \& Machado, P. F. (2009). Sazonalidade do teor de proteína e outros componentes do leite e sua relação com programa de pagamento por qualidade. Arquivo Brasileiro de Medicina Veterinária e Zootecnia, 61(6):14111418.

Simioni, F. J., Sâmia Lopez, L., Nespolo, C. R., Moura Stefani, L., Bordignon, R. \& Bittelbrun, M. S. (2014). Season influence on milk physico-chemical and microbiological aspects in Western Santa Catarina. Semina: Ciências Agrárias, 35(4):2033-2046.

Souza, R., Santos, G. T., Valloto, A. A., Santos, A. L., Gasparino, E., Silva, D. C. \& Santos, W. B. R. (2010). Produção e qualidade do leite de vacas da raça Holandesa em função da estação do ano e ordem de parto. Revista Brasileira de Saúde e Produção Animal, 11(2).

Taffarel, L. E., Costa, P. B., Tsutsumi, C. Y., Klosowski, E. S., Portugal, E. F. \& Lins, A. C. (2015). Variação da composição e qualidade do leite em função do volume de produção, período do ano e sistemas de ordenha e de resfriamento. Semina: Ciências Agrárias, 36(3-Supl-1):2287-2300.

Recebido: 24 fevereiro, 2019

Aprovado: 15 de março, 2019.

Publicado: 29 de abril, 2019.

Licenciamento: Este artigo é publicado na modalidade Acesso Aberto sob a licença Creative Commons Atribuição 4.0 (CC-BY 4.0), a qual permite uso irrestrito, distribuição, reprodução em qualquer meio, desde que o autor e a fonte sejam devidamente creditados. 